PLPB: Pendidikan Lingkungan dan Pembangunan Berkelanjutan

DOI: https://doi.org/10.21009/PLPB.171.03

DOI: 10.21009/PLPB

\title{
PERBEDAAN PENGETAHUAN IBU-IBU TENTANG ISU-ISU LINGKUNGAN ANTARA STRATEGI PENYULUHAN OUT GROUP VERSUS IN GROUP BERDASARKAN KEPEDULIAN LINGKUNGAN
}

\author{
Robert Zachariasz \\ e-mail: rzachariasz@yahoo.com
}

\begin{abstract}
The objective of this research is to analyze the effect of extension strategy and the environmental concern on knowledge about environmental issues of house wives on the slums in West Jakarta. The sample of the research was 40 housewives, which selected randomly. The data were analyzed by using ANOVA with $2 \times 2$ factorial design. The result of the research reveals that: 1) the knowledge about environmental issues of housewiveswho received extension strategy by out group extension agents have not more highly than when they received extension by in group extension agents; 2) The housewives who have high environmental concern and receive extension by out group extension agents have more highly knowledge about environmental issues than when they received extension by in group extension agents; 3)The housewives who have low environmental concern and received extension by out group extension agents have lower knowledge about environmental issues than when they received extension by ingroup extension agents; 4) There are interaction effects between extension strategy and the environmental concern towards the housewives knowledge about environmental issues.
\end{abstract}

Kata Kunci: pengetahuan isu-isu lingkungan, strategi penyuluhan out-group dan in-group, dan kepedulian lingkungan.

\begin{tabular}{|l|l|l|l|}
\hline Volume XVII & Nomor 01 & Maret 2016 & ISSN 1411-1829 \\
\hline
\end{tabular}




\section{Pendahuluan}

Pada dasarnya sumber kerusakan lingkungan hidup bertumpu kepada aspek manusia itu sendiri. Sejauh ini teori antroposentris dituduh sebagai salah satu penyebab, bahkan penyebab utama dari krisis lingkungan hidup, karena para penganut antroposentris cenderung memiliki pola perilaku yang eksploitatif, destruktif demi kepentingannya sendiri tanpa peduli terhadap alam (Keraf, 2010).

Di pihak lain konsumsi berlebihan oleh dunia maju telah menimbulkan suatu masalah lingkungan dengan adanya eksploitasi besar-besaran atas sumber daya alam yang telah menimbulkan kerusakan hutan, tanah, air, udara dan iklim tanpa dapat diperbaiki kembali (Attfield, 2010).

Oleh karena itu sekarang ini manusia harus belajar memahami lingkungannya demi dirinya sendiri (Mars 1863). Besarnya kelompok lapisan masyarakat miskin yang menghuni berbagai tempat di perkotaan dan masih minimnya pengetahuan tentang lingkungan, merupakan fakta di dalam kehidupan sehari-hari yang turut mendorong manusia tidak dapat memperlakukan lingkungan dengan baik. Oleh karena itu, perlu dibangun kesadaran tentang hubungan antar manusia dengan lingkungan maupun makhluk hidup lainnya dalam satu ekosistem.

Kesadaran lain yang perlu dimiliki oleh masyarakat adalah tentang isu-isu lingkungan yang kini sudah sangat serius melanda bumi ini. Isu-isu lingkungan yang telah muncul saat ini dulunya tidak pernah ada, seperti penipisan ozon, gas rumah kaca, kenaikan suhu bumi, kenaikan permukaan air laut, perubahan garis pantai, kerusakan hutan, El Nino, La Nina dan yang sangat beresiko mengancam kehidupan makhluk hidup yaitu perubahan iklim akibat adanya pemanasan global. (Hackett 1995)

Selain itu, beberapa isu lingkungan, seperti: adanya gejala penggundulan, pencemaran tanah karena pemakaian pupuk, pencemaran laut, pertumbuhan penduduk yang sangat cepat. Isu lingkungan menyangkut kehidupan margasatwa.

Sepanjang sejarah, manusia menggunakan pengetahuannya untuk mengontrol lingkungannya, membentuknya dan mengamankannya agar hidupnya bisa sukses dan harmonis (Chiras 1991). Semua pengetahuan yang ada pada seseorang tidak akan berguna jika tidak dapat digunakan secara baik untuk menata hidupnya dengan komunitas di sekitarnya. Demikian juga lingkungan dimana kita hidup adalah lingkungan hidup manusia, maka sudah pasti di sana manusia mempunyai kepentingan. 
Oleh karena itu, manusia harus mempunyai kesadaran hidup di lingkungannya supaya dapat memperoleh hasil yang memuaskan, termasuk hubungannya dengan spesies lain dalam satu ekosistem (Soedjatmoko, 1991).

Isu-isu lingkungan ini penting diketahui oleh masyarakat dunia supaya dapat diantisipasi dan ditanggulangi bersama, karena efek dari isu-isu lingkungan berdampak langsung kepada manusia. Salah satu solusi untuk meningkatkan pengetahuan masyarakat tentang isu-isu lingkungan adalah melalui penyuluhan. Oleh karena itu, perlu ada satu penelitian strategis mengenai isu-isu lingkungan, dengan tujuan: 1) menambah pengetahuan ibu-ibu; 2) memaksimalkan peranan tokoh masyarakat; dan 3) mencari satu strategi baru (Kantor KLH, 1997: 14).

Strategi penyuluhan harus berangkat dari asumsi mendasar dalam kehidupan masyarakat, yaitu: "getting better together" atau raihlah yang lebih baik secara bersamasama (Stahl,1994).

Penyuluhan sebenarnya adalah sebuah bentuk pertolongan yang diberikan kepada orang, sebab secara tradisional penyuluhan itu memberikan nasehat (Feltham,1995). Sisi lain dari penyuluhan adalah pendidikan yang harus memberikan "penyadaran" (conscientization) terhadap situasi. Ini berarti penyuluhan harus memberikan penyadaran kepada individu agar menyadari existensinya, termasuk berbagai masalah yang ada di sekitarnya (Paulo Freire,1972). Karena pengetahuan seseorang dapat membentuk kepribadian (Krech,1962). Penelitian ini mengamati strategi penyuluhan dari dua sumber informasi yaitu dari luar (out group) antara lain pihak pemerintah dalam hal ini Dinas yang berhubungan dengan permasalahan lingkungan atau dari Lembaga Swadaya Masyarakat dan dari pihak masyarakat sendiri, yaitu individu atau kelompok "orang dalam" (in group) yang bisa membagikan pengetahuannya kepada sesama warga. Tujuan penyuluhan adalah membantu sesama dan masyarakat agar mereka dapat membuat keputusan yang benar, meningkatkan kepedulian dan membangkitkan kesadaran mereka (Van den Ban dan Hawkins, 1996).

Indikator lain yang berkaitan dengan faktor pengetahuan dan faktor penyuluhan adalah faktor kepedulian lingkungan, yang dalam penelitian ini dilihat dari dua segi, yaitu kepedulian lingkungan tinggi dan kepedulian lingkungan rendah.

Konsep kepedulian lingkungan (environmental concern) muncul pertama kali ketika masyarakat merubah 
pandangannya tentang lingkungan hidup.

Semua orang mempunyai kepedulian terhadap lingkungan, akan tetapi kadar kepeduliannya ada yang tinggi, ada yang rendah (Unesco, 1991). Kepedulian lingkungan hidup adalah suatu cara manusia untuk melestarikan alam agar tidak terganggu oleh manusia-manusia yang tidak bertanggung jawab (Miller,1993). Kepedulian itu harus mulai dari keluarga sendiri, dimana mulai dari menciptakan kebersihan di dalam rumah dan di sekitar rumah. Ketidakpedulian terhadap lingkungan hidup akan menyebabkan timbulnya berbagai krisis lingkungan hidup. Untuk itu perlu adanya kepedulian yang tinggi terhadap lingkungan. Juga ada sebuah pandangan baru terhadap isu-isu lingkungan yang diperlukan kepedulian terhadap lingkungan menyangkut dengan nilai, etika, sikap dan perilaku (Bechel,1993). Oleh karena itu, para pemimpin dunia harus mengambil langkah-langkah nyata untuk menanggulangi krisis lingkungan global ( Gore,1993).

Ada beberapa penelitian yang mencatat hasil penelitian tentang isu-isu lingkungan seperti: 1) Prelle dan Solomon (1996) menggunakan sembilan isu-isu lingkungan dalam meneliti isu-isu lingkungan di kalangan pemuda untuk mengetahui pengetahuan dan sikap para pemuda tentang isu-isu lingkungan. 2) Ines, Hungerfort dan Tomera (1986) meneliti isuisu lingkungan di kalangan pemuda telah menemukan beberapa variabel tentang sikap yang bertanggungjawab seperti: pengetahuan tentang isu-isu lingkungan, sikap dan tanggungjawab pribadi. 3) Van Lire dan Dunlock (1981) memberikan satu model tentang kepedulian lingkungan yang diperoleh dari hasil penelitian tentang hubungan antara karakteristik sosiodemografik (umur, sex dan sebagainya) dan kepedulian lingkungan (Asunta, 2003).

Penelitian yang kami lakukan, bertujuan untuk mengetahui seberapa besar pengaruh penyuluhan yang diberikan kepada warga dapat memengaruhi citra dan kepedulian mereka terhadap lingkungannya dan meningkatkan pengetahuan mereka khususnya tentang isu-isu lingkungan.

Berdasarkan latar belakang masalah di atas, maka dapat dirumuskan hipotesis dalam penelitian ini, sebagai berikut:

1. Pengetahuan ibu-ibu tentang isu-isu lingkungan yang mendapat strategi penyuluhan out group lebih tinggi dari pada ibu-ibu yang mendapat strategi penyuluhan in group;

2. Terdapat pengaruh interaksi antara 
strategi penyuluhan dan kepedulian lingkungan terhadap pengetahuan ibu-ibu tentang isu-isu lingkungan;

3. Pengetahuan ibu-ibu tentang isu-isu lingkungan bagi yang mempunyai kepedulian lingkungan tinggi yang mendapat strategi penyuluhan out group, lebih tinggi daripada ibu-ibu yang mendapat strategi penyuluhan in group;

4. Pengetahuan ibu-ibu tentang isu-isu lingkungan bagi yang mempunyai kepedulian lingkungan rendah yang mendapat strategi penyuluhan outgroup lebih rendah daripada ibu-ibu yang mendapat strategi penyuluhan in-group.

\section{Metodologi Penelitian}

Metode penelitian yang digunakan adalah metode eksperimen dengan tiga variabel, yaitu:

1. Variabel terikatnya adalah pengetahuan ibu-ibu tentang isu-isu lingkungan;

2. Variabel bebas perlakuan adalah strategi penyuluhan, yang terdiri dari penyuluhan dari orang luar (out group) dan penyuluhan dari orang dalam (in group);

3. Variabel bebas lain sebagai atribut adalah tingkat kepedulian lingkungan, yang dibagi dalam dua tingkatan yaitu kepedulian tinggi dan kepedulian rendah.

Rancangan eksperimen yang digunakan dalam penelitian adalah Desain Faktorial 2 x 2 dengan matriks rancangan eksperimen.

Sampel terjangkau dipilih dari ibu-ibu dari Kampung Apung Kapuk yaitu satu nama kampung yang berada dalam Kelurahan Kapuk, salah satu dari 6 Kelurahan di Kecamatan Cengkareng. Mereka tinggal di satu Rukun Warga, dan sebanyak 60 orang dipilih untuk diberikan penyuluhan. Peserta penyuluhan dibagi menjadi dua kelompok perlakuan, 30 orang peserta mendapat strategi penyuluhan out group dan 30 orang mendapat strategi penyuluhan in group. Sampel yang diambil adalah $33 \%$ (Netko,1996).

Jenis data yang dikumpulkan dalam penelitian adalah data pengetahuan ibu-ibu tentang isu-isu lingkungan, dan data tentang kepedulian lingkungan, dengan menggunakan teknik analisis data diskriptif dan analisis inferensial. Analisis deskriptif disajikan melalui tabel distribusi frekwensi, rata-rata, simpangan baku dan histogram. Analisis inferensial digunakan untuk menguji hipotesis. Sebelum dilakukan pengujian hipotesis terlebih dahulu 
dilakukan uji normalitas data dengan uji Kolmogorov Smirnov dan uji homogenitas varians dengan Uji Bartlett.

Untuk menguji hipotesis digunakan analisis varian (ANAVA) dua jalur yang akan membandingkan angka $F_{\text {hitung dengan }}$ $F_{\text {tabel }}$ pada setiap faktor perlakuan (A dan B) serta interaksi antar faktor (A x B).

\section{Hasil Penelitian Dan Pembahasan}

Pada uji hipotesis pertama merupakan eksperimen yang dimaksudkan untuk mengetahui pengaruh perlakuan, yakni strategi penyuluhan out group. Dalam pelaksanaan eksperimen ibu-ibu yang dikelompokkan menjadi dua kelas, masingmasing diberikan penyuluhan dengan strategi yang berbeda. Kelas yang diberikan strategi penyuluhan out group $\left(\mathrm{A}_{1}\right)$ dalam disain eksperimen ini lebih diunggulkan dibandingan dengan kelas yang diberikan strategi penyuluhan in group $\left(\mathrm{A}_{2}\right)$.

Hasil uji pada, menunjukkan bahwa untuk hipotesis kesatu (baris sumber variasi Strategi Penyuluhan) diperoleh harga $F_{\text {hitung }}=1,66^{\text {ns }}<F_{(0,95)(1: 36)}=4,11$. Hasil uji menunjukkan terima Ho pada $\alpha=0,05$. Hipotesis kesatu yang menyatakan "pengetahuan tentang isu-isu lingkungan ibu-ibu yang mendapat strategi penyuluhan out group lebih tinggi daripada ibu-ibu yang mendapat strategi penyuluhan in group" tidak teruji kebenarannya (non signifikan). Hal ini ditunjukkan dengan fakta bahwa, rata-rata skor pengetahuan tentang isu-isu lingkungan ibu-ibu yang mendapat strategi penyuluhan out group tidak lebih tinggi daripada ibu-ibu yang mendapat strategi penyuluhan in group. Hasil uji ini berarti bertolak belakang dengan kerangka teoretik kesatu yang digunakan sebagai dasar dalam pengajuan hipotesis ini.

Pada uji hipotesis kedua dimaksudkan untuk membuktikan secara empirik pengaruh interaksi (A x B). Kriteria hasil uji yang digunakan adalah terima Ho jika harga $\mathrm{F}_{\text {tabel }}<\mathrm{F}_{\text {hitung }}<\mathrm{t}_{\text {tabel }}$ pada $\alpha=0,05$ dan derajat kebebasan $(\mathrm{dk})=\left(\mathrm{v}_{1} ; \mathrm{v}_{2}\right)$ yaitu: $\mathrm{F}_{0,95(1 ; 36)=}$ 4,11. Dari hasil uji yang diringkas dalam Tabel 2 diperoleh harga $\mathrm{F}_{(0,95)(1,36)}=$ $4,11<\mathrm{F}_{\text {hitung }}=\quad 7,17 * \quad>\mathrm{F}_{(0,95)(1,36)}=4,11$. Adanya pengaruh interaksi dapat digambarkan dengan estimasi harga mean untuk masing-masing level variabel penelitian dapat dilihat pada gambar 1: 


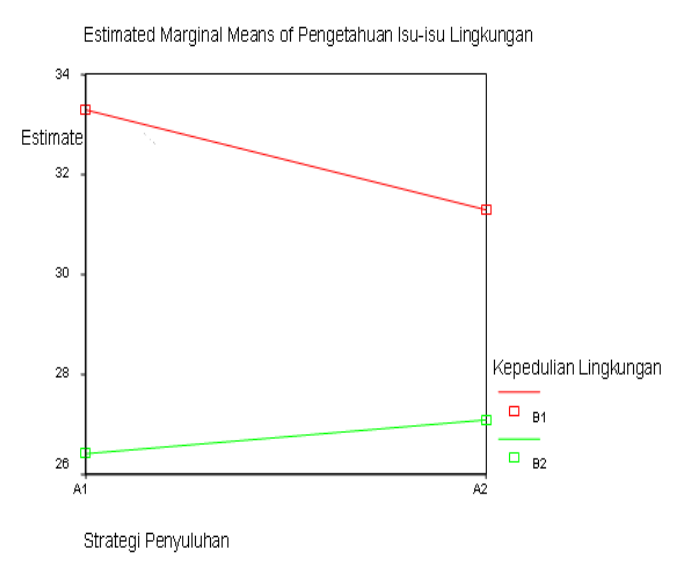

Gambar 1. Grafik Interaksi

Hasil uji ini menunjukkan Ho berada di luar daerah penerimaan Ho atau tolak Ho pada $\alpha=0,05$, ini berarti memberikan bukti secara empirik bahwa "pengaruh interaksi antara strategi penyuluhan dan kepedulian lingkungan terhadap pengetahuan ibu-ibu tentang isu-isu lingkungan"adalah teruji secara signifikan. Dengan adanya pengaruh interaksi di atas, maka tinggi rendahnya pengetahuan tentang isu-isu lingkungan dalam penelitian ini harus dilihat berdasarkan faktor tinggi atau rendahnya kepedulian lingkungan.

Pengaruh interaksi A x B memberikan hasil yang signifikan. Hasil uji tersebut memberikan konsekuensi untuk dilakukan pengujian hipotesis berikutnya yakni hipotesis ketiga dan keempat yang menguji adanya efek dari interaksi antara strategi penyuluhan dan kepedulian lingkungan. Dalam uji hipotesis ini dilakukan dengan uji post hoc Tukey.

Pada uji hipotesis kedua merupakan uji pengaruh faktor dari variabel $\mathrm{X}_{2}$ yang dimaksudkan untuk mengetahui pengaruh perlakuan, yakni strategi penyuluhan out group $\left(\mathrm{A}_{1}\right)$ dan in group $\left(\mathrm{A}_{2}\right)$ berdasarkan faktor kepedulian lingkungan tinggi $\left(b_{1}\right)$.

Dengan kriteria hasil uji adalah tolak Ho jika harga $Q_{\text {hitung }}>Q_{\text {tabel }}$. Hasil uji Post Hoc Tukey menunjukkan bahwa harga $\mathrm{Q}_{\text {hitung }}=7,17 *>\mathrm{Q}_{(0,95)(18)}=4,49$. Hasil uji adalah tolak Ho pada $\alpha=0,05$. Hipotesis ketiga yang menyatakan Pengetahuan tentang isu-isu lingkungan ibu-ibu yang mempunyai kepedulian lingkungan tinggi yang mendapat strategi penyuluhan out group lebih tinggi daripada ibu-ibu yang mendapat strategi penyuluhan in group teruji kebenarannya (signifikan).

Pada uji hipotesis ketiga merupakan uji pengaruh faktor dari variabel $\mathrm{X}_{2}$ yang dimaksudkan untuk mengetahui pengaruh perlakuan, yakni strategi penyuluhan out group $\left(\mathrm{A}_{1}\right)$ dan in group $\left(\mathrm{A}_{2}\right)$ berdasarkan faktor kepedulian lingkungan rendah $\left(b_{2}\right)$. Untuk kepentingan analisis maka pengaruh perlakuan diuji berdasarkan faktor $b_{2}$. Pada uji hipotesis keempat dilakukan dengan uji post hoc Tukey.

Dengan kriteria hasil uji adalah tolak 
Ho jika harga $Q_{\text {hitung }} \leq Q_{\text {tabel. Hasil uji Tukey }}$ menunjukkan bahwa harga $\mathrm{Q}_{\text {hitung }}=1,07 *<$ $\mathrm{Q}_{(0,95)(18)}=4,49$. Hasil uji adalah tolak Ho pada $\alpha=0,05$. Hipotesis keempat yang menyatakan Pengetahuan tentang isu-isu lingkungan ibu-ibu yang mempunyai kepedulian lingkungan rendah yang mendapat strategi penyuluhan out group lebih rendah daripada ibu-ibu yang mendapat strategi penyuluhan in group teruji kebenarannya (signifikan).

\section{Kesimpulan}

Berdasarkan analisis data dan pembahasan yang telah dijelaskan di atas maka dapat disimpulkan, sebagai berikut:

Pertama, rata-rata skor pengetahuan ibu-ibu tentang isu-isu lingkungan yang mendapat strategi penyuluhan out group tidak lebih tinggi daripada ibu-ibu yang mendapat strategi penyuluhan in group.

Kedua, terdapat pengaruh interaksi antara strategi penyuluhan dan kepedulian lingkungan terhadap pengetahuan Ibu-ibu tentang isu-isu lingkungan.

Ketiga, rata-rata skor pengetahuan ibu-ibu tentang isu-isu lingkungan untuk kategori kepedulian lingkungan tinggi dan mendapat strategi penyuluhan out group lebih tinggi daripada yang mendapat strategi penyuluhan in group.
Keempat, rata-rata skor pengetahuan ibu-ibu tentang isu-isu lingkungan untuk kategori kepedulian lingkungan rendah dan mendapat strategi penyuluhan out group lebih rendah daripada yang mendapat strategi penyuluhan in group.

\section{Daftar Pustaka}

Agarwal, Bina. "The Gender and Environment Debate”, David Pepper, Frank Webster and George Refill (ed), Environmentalism, Critical Concepts Volume II. London \& New York: Routledge, 2003.

Asunta, Tuula. Knowledge of Environmental Issues, Where Pupils Acquire Information Opinions, and How it Affects their Attitudes, and Laboratory Behaviour. Jyväskylä: University Printing House, 2003.

Attfield, Robin.Etika Lingkungan Global, terjemahan Saut Pasaribu,Penerbit Kreasi Wa-cana, Bantul, 2010

Bechel, Robert B. Environmental and Behavior, London: A Division of SAGE Publications Inc, 1993.

Chiras, Daniel D. Environmental Science, Action for a Sustainable Future $3^{\text {rd }} \mathrm{Ed}$. California: The Benyamin/Cummings Publishing Company, Inc., 1991.

Freire, Paulo. Paedagogy of the Oppressed, .New York, Herder and Herder, 1972.

Gore, Al.. Earth Vice President.Earth in Balance: Ecology and the Human Spirit. New York: First Plume Printing, 1993.

Güven, Seval., et al. "Elementary School Students Knowledge about environment Issue in Turkey", International Journal of Bussiness and 
Social Science, Vol. 2 No. 4, March 2011.

Hackett, Paul. Concervation and the Consumer, Understanding Environment Concern. London dan New York: Routledge, 1995.

Hatfield, Susan Buckingham. Gender and Environment. London \& New York: Routledge, 2000.

Kantor Menteri Lingkungan Hidup. Agenda 21 Indonesia, Strategi Nasional Dalam Pembangunan Berkelanjutan. Jakarta: Kantor Menteri Lingkungan Hidup, 1997.

Keraf, A. Sonny.Etika Lingkungan Hidup, Jakarta, Gramedia, 2010.

Krech, David., Crutchfield and Ballachey L. Egerton, Individual in Society, Tokyo, Mc Graw Hill Kogakusha 1td, 1962

Marsh, George Perkins, Man and Nature, Phisical Geography. New York,
Charles Scribner, 124 Grand Street, 1864.

Miller, G.Tyler. Living in the Environment Concepts, Problems and Altenatves. California: Wadsworth Publication, Inc. 1993.

Nitko, Anthony J. Educational Assessment of Students, Third Edition, New Jersey, Merril Prentice Hall, 2001.

Soedjatmoko, Soedjatmoko dan Keprihatinan Masa Depan. Yogyakarta: Tiara Wacana, 1991.

Stahl, Robert J., Cooperative Learning in Social Studies, Handbook for Teacher, USA, 1994.

UNESCO-UNEP. Environmental Education. Newsletter, 1991.

Van den Ban, A.W., H.S Hawkins. Agricultural Extension, $2^{\text {nd }}$ ed., Oxford, Blackwell Sciece 1996.

\begin{tabular}{|l|l|l|l|}
\hline Volume XVII & Nomor 01 & Maret 2016 & ISSN 1411-1829 \\
\hline
\end{tabular}

